\title{
A Study on Vision Disability Compensation Provided to Students at Qassim University, Saudi Arabia
}

\author{
Khalid M. Alabdulwahhab ${ }^{1}$, Mohammad Shakil Ahmad² \\ ${ }^{1}$ Department of Ophthalmology, College of Medicine, Majmaah University, \\ Almajmaah, Saudi Arabia. ${ }^{2}$ Department of Community Medicine and Public Health, \\ College of Medicine, Majmaah University, Almajmaah, Saudi Arabia.
}

\section{ABSTRACT}

\section{BACKGROUND}

Visual disability is one of the most significant global health concerns. One of the studies conducted in northern part of Saudi Arabia showed that the prevalence of visual disability in adult population of $23.5 \%$. Very few studies have been conducted in Saudi Arabia to determine the prevalence of visual disability in the younger population. We wanted to determine the prevalence of visual disability in students studying at Qassim University. We also wanted to study and compare the utilization of compensatory rehabilitation by the students of urban and rural areas and the subjective response of beneficiaries.

\section{METHODS}

This study was done from September 2011 to May 2012, in the Department of Optometry in Qassim University, Buraidah, Kingdom of Saudi Arabia. A crosssectional retrospective review from the records of 642 male students referred by the deanship of student's affairs to the optometry clinic were studied.

\section{RESULTS}

The prevalence of visual disability in this study was found to be $2 \%$. Out of the total 642 students, a significant number of students [541 (84\%)] benefited from the scheme and 101 (16\%) were declared normal. Those who were declared visually disabled (2\%) were getting compensation on monthly basis and the remaining $82 \%$ with mild to moderate visual problems benefitted with spectacles. More number of urban students were suffering from visual abnormalities (87.6 \%) as compared to rural students ( $45.1 \%)$.

\section{CONCLUSIONS}

Though visual disability among young population at Qassim University was found to be low as compared to adult population is Saudi Arabia, it is recommended to conduct regular check-ups for visual acuity and plan to reduce the magnitude of the problem. A significant number of students utilized the compensation and rehabilitation program provided by the department of optometry.

\section{KEY WORDS}

Refractive Error, Blindness, Student Compensation, Qassim University, Saudi Arabia
Corresponding Author:

Dr. Mohammad Shakil Ahmad,

Department of Community Medicine,

\& Public Health, College of Medicine,

Majmaah University,

Al Majmaah -11952 Saudi Arabia,

E-mail: m.shakil@mu.edu.sa

DOI: $10.14260 /$ jemds/2021/167

How to Cite This Article:

Alabdulwahhab KM, Ahmad MS. A study on vision disability compensation provided to students at Qassim University, Saudi Arabia. J Evolution Med Dent Sci 2021;10(11):779-783, DOI: $10.14260 /$ jemds/2021/167

Submission 23-09-2020,

Peer Review 12-12-2020,

Acceptance 18-12-2020,

Published 15-03-2021.

Copyright (C) 2021 Khalid M. Alabdulwahhab et al. This is an open access article distributed under Creative Commons Attribution License [Attribution 4.0 International (CC BY 4.0)] 


\section{BACKGROUND}

One of the most predominant phenomena occurring globally is disability and it is estimated that $15 \%$ of the world's population lives with some kind of disability, 2 - $4 \%$ face considerable problems in functioning (World Report on Disability, 2011). ${ }^{1}$

The country of Saudi Arabia has a population of 27.1 million people including about 9.4 million expatriates. During the last few decades there has been a drastic shift in place of residence from rural to urban, there are estimates that over 95 $\%$ of population is now residing in urban areas and remaining $5 \%$ are nomads. Saudi Arabia's capital city Riyadh holds a population of about 6.5 million. The latest statistics show that the population in the Qassim region is $1,016,756.2$

Kingdom of Saudi Arabia caters to the social needs of the people by providing special services for the deprived sections and are considered extensive by any standards. These services are directed to correct the current imbalances and to improve the quality of living of its citizens by community participation and development related activities. Basically, they provide rehabilitation and assistance for the deprived people. ${ }^{3}$

Blindness and low vision, are one of the most common disabilities among students and elderly population, there are many rehabilitation clinics set up for the correction of visual disabilities in Saudi Arabia. ${ }^{3}$ In Saudi Arabia the law states for mandatory provision of benefits for all the disabled university students. The study aims to research on the utilisation of low vision / disability services by the students of Qassim University. The visual disability test criteria are based on the 22 WCO (World Council of Optometry criteria) for visual disability and WHO (World Health Organization) guidelines.

\section{METHODS}

This is a cross-sectional retrospective review of the record of 642 students visiting the optometry clinics in the Department of Optometry at Qassim University from December 2010 to March 2011. A questionnaire was used to collect the detailed ocular and systemic history with a detailed report of the eye examination. All the participants in this study underwent a comprehensive examination of their eyes using visual acuity projector, streak retinoscope, auto refractometer, slit lamp bio microscope, direct and indirect ophthalmoscope and the assessment included visual acuity assessment, objective and subjective refraction, ocular mortality test, cover test, pupillary evaluation, anterior and posterior segment examination. Visual field analysis with automated perimetry was carried out on students as part of the examination of the field of vision.

Spectacle and contact lenses were prescribed to the participants who were found to have poor visual acuity. Mild and moderate cases of refractive errors were mostly managed with prescription of spectacles. Students with high amount of refractive errors were prescribed contact lenses to improve their visual acuity. Irregular astigmatism was corrected by specialty, rigid and hybrid contact lenses. Prescription of spectacles was purely after cycloplegic refraction in cases of difficult clinical situations. Low refractive errors were given prescriptions based on symptomology and need for visual correction in certain optometric conditions. Poor visual acuity in students in-spite of spectacles or contact lenses were categorised as low vision or visually impaired based on WHO criteria of visual impairment. ${ }^{4}$

\section{Uncorrected Refractive Error Definitions}

Uncorrected Refractive Error (RE) was defined as a 2-line improvement with refraction in the better eye. Unmet refractive need was defined as having $<20 / 40$ visual acuity in the better eye and achieving $\geq 20 / 40$ after refraction (definition 1), or having $<20 / 40$ visual acuity in the better eye and achieving $\mathrm{a} \geq 2$-line improvement with refraction (definition 2). ${ }^{5}$ Uncorrected VA (Visual Acuity) was defined using unaided VA, presenting VA was defined using spectacle corrected acuity, if worn. Hence, students were considered in need of refractive correction if uncorrected VA was less than $20 / 40$ in the better eye, which improved by at least two lines with refractive correction. The 20 / 40 VA threshold used in defining need coincided with the definition of visual impairment used in RESC (Refractive Error in School Children) studies. Students with spectacles were considered under corrected if presenting VA in the better eye was improved by at least 2 lines with refraction (definition 3). Subjects who were not using optical correction and who had distance VA of 20 / 20 or better were considered as emmetropes. Children whose vision is not fully correctable because of amblyopia or pathological changes were not separated from those considered to be in need of refractive correction when VA improvement of two or more lines could be achieved. ${ }^{6}$

\section{Refraction Measurements - Refractive Error Classification}

$\mathrm{RE}$ is classified into myopia, hyperopia and astigmatism. Refraction measurements were expressed as Spherical Equivalents (SE). The age-specific and gender-specific prevalence of myopia $\leq-0.50$ SE diopters (D) and of hyperopia $\geq 2.0 \mathrm{SE}$ diopters were calculated. Myopia was categorised as mild ( $-0.50 \mathrm{D}$ to $-3.0 \mathrm{D})$, moderate $(-3.1 \mathrm{D}$ to -6.0 D) and high (>-6.0 D). Hyperopia was categorised as mild ( $+2.0 \mathrm{D}$ to $+3.9 \mathrm{D})$, moderate ( $+4.0 \mathrm{D}$ to $+5.9 \mathrm{D})$, and high $(\geq+6.0 \mathrm{D})$. Astigmatism was defined as cylinder $\geq 0.75 \mathrm{D}$. Anisometropia was defined as an interocular difference of $\geq 1 \mathrm{D}$ SE. All definitions referred to values obtained after cycloplegic auto refraction. Astigmatism was further analysed by dividing the subjects into three types: myopic astigmatism (compound myopic astigmatism and simple myopic astigmatism), hyperopic astigmatism (compound hyperopic astigmatism and simple hyperopic astigmatism) and mixed astigmatism. ${ }^{7}$

All the students referred for examination for visual acuity by the Deanship of Students Affairs Department, Qassim University were included in this study.

\section{Ethical Approval}

Ethics and Research Committee of the College of Applied Medical Sciences \& Qassim University provided clearance for carrying out the study. Informed consent was obtained from each student and participation was voluntary. The questionnaire for the demographic data collection from participants was excluded from furnishing names to maintain confidentiality. 


\section{Statistical Analysis}

The data was entered, cleaned and validated using Excel spread sheet. Mean and standard deviation was computed for quantitative variables. Frequency / percentages computed and graphs prepared for categorical variables. The association between categorical variables was analysed by using chisquare test. Statistical software SPSS version-20 was used for the statistical analysis. P-value $<0.05$ was considered statistically significant.

\section{RESULTS}

Qassim University has an approximate of 70,000 students and a total of 642 students were referred by Students' Affairs Department for screening. The average age of students was $20.02 \pm 3.15$. Majority of them come from urban area (92\%) and very few ( $8 \%$ ) from rural. Of the total 642 students 541 (84\%) students were found to have poor visual acuity and utilised the scheme and 101 (16\%) students declared normal. About $82 \%$ students were provided with spectacles and only $13(2 \%)$ students were found to suffer with low vision or visually impairment. These visually disabled students availed disability compensation. (Figure 1)

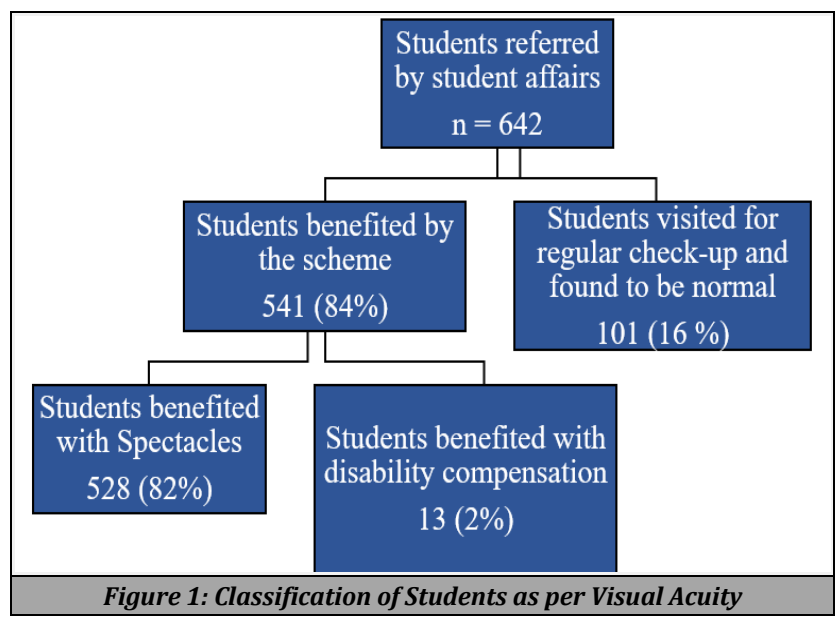

\begin{tabular}{|ccccc|}
\hline Residence Type & $\begin{array}{c}\text { Refractive Error } \\
\text { N (\%) }\end{array}$ & $\begin{array}{c}\text { Normal } \\
\text { N (\%) }\end{array}$ & $\begin{array}{c}\text { Total } \\
\text { N (\%) }\end{array}$ & $\begin{array}{c}\text { Chi- } \\
\text { Square Value }\end{array}$ \\
\hline Rural & $23(45.1 \%)$ & $28(54.9 \%)$ & $41(100 \%)$ \\
Urban & $518(87.6 \%)$ & $73(12.4 \%)$ & $601(100 \%)$ & $64.117<0.001 *$ \\
\hline Total & $541(84.3 \%)$ & $101(15.7 \%)$ & $642(100 \%)$ \\
\hline \multicolumn{5}{|c|}{ Table 1. Distribution of Significant Refractive Error } \\
between Urban and Rural Students \\
\hline *Statistically significant at P < 0.001 \\
\hline \multicolumn{5}{|c|}{} \\
\hline
\end{tabular}

There was high association observed between residence type and refractive error. More number of urban students had significant refractive error (87.6\%) as compared to rural (45.1 $\%)$. The difference was found statistically significant $(\mathrm{p}<$ 0.001), (Table 1).

Of the total cases (227) having spherical refractive error $186(82 \%)$ were suffering from mild to moderate myopia while the rest had other conditions like hyperopia and severe myopia. Of the total cases (314) having cylindrical refractive error, majority 267 (85\%) had mild to moderate astigmatism and 47 had severe to extreme condition (Table 2).

\begin{tabular}{|c|c|c|}
\hline Refractive Error Type & Frequency & Percentage \\
\hline \multicolumn{3}{|c|}{ Spherical Refractive Error } \\
\hline Hyperopia (Severe to Extreme) & 5 & $2 \%$ \\
\hline Hyperopia (Mild to Moderate) & 28 & $12 \%$ \\
\hline Myopia (Severe to Extreme) & 8 & $4 \%$ \\
\hline Myopia (Mild to Moderate) & 186 & $82 \%$ \\
\hline Total & 227 & $100 \%$ \\
\hline \multicolumn{3}{|c|}{ Cylindrical Refractive Error } \\
\hline Astigmatism (Severe to Extreme) & 47 & $15 \%$ \\
\hline Astigmatism (Mild to Moderate) & 267 & $85 \%$ \\
\hline Total & 314 & $100 \%$ \\
\hline \multicolumn{3}{|c|}{ Table 2. Morbidity Profile } \\
\hline Visual Acuity & UCVA (\%) & BCVA (\%) \\
\hline$\leq 6 / 30$ on both eye & $248(45.8)$ & $486(89.9)$ \\
\hline$\leq 6 / 30$ on left eye and $\geq 6 / 60$ on right eye & $47(8.6)$ & $17(3.1)$ \\
\hline$\leq 6 / 30$ on right eye and $\geq 6$ / 60 on left eye & $62(11.5)$ & $28(5.2)$ \\
\hline$\geq 6 / 60$ on both eye & $184(34.1)$ & $10(1.8)$ \\
\hline Total & $541(100.0)$ & $541(100.0)$ \\
\hline \multicolumn{3}{|c|}{$\begin{array}{l}\text { Table 3. Comparison of Uncorrected Visual Acuity and } \\
\text { Best Corrected Visual Acuity }\end{array}$} \\
\hline
\end{tabular}

A significant number of changes was observed in visual acuity of cases before and after correction. Around $90 \%$ of the cases had visual acuity of $\leq 6 / 30$ on both eye after correction, while it was $46 \%$ before correction. About $34 \%$ of cases had visual acuity of $\geq 6$ / 60 on both eyes before correction while it was $1.8 \%$ after correction. (Table 3 )

\begin{tabular}{|c|c|c|c|}
\hline \# & Causes & Frequency & Percent \\
\hline 1 & $\begin{array}{l}\text { Bilateral sub capsular cataract resulting into } \\
\text { stimulus deprivation Amblyopia }\end{array}$ & 4 & 30.77 \\
\hline 2 & High pathological Myopia & 1 & 7.69 \\
\hline 3 & Bilateral severely advanced Keratoconus & 2 & 15.38 \\
\hline 4 & Bilateral visual fields constriction & 2 & 15.38 \\
\hline 5 & Homonymous quadrantanopia & 2 & 15.38 \\
\hline 6 & $\begin{array}{l}\text { Night blindness due to bilateral retinitis } \\
\text { pigmentosa } \\
\text { resulting into peripheral visual field loss }\end{array}$ & 2 & 15.38 \\
\hline & Total & 13 & 100 \\
\hline \multicolumn{4}{|c|}{ Table 4. Causes in Visually Disabled Students } \\
\hline
\end{tabular}

A total of 13 students were detected with visual disability. The disabilities were of varying characteristics. Among the total disabled 4 had bilateral sub capsular cataract resulting into stimulus deprivation amblyopia and 1 had high pathological myopia (Table 4).

After the successful treatment and correction of the visual disabilities, the students were assisted for better life in various fields and professions for an independent future, as the students with visual disabilities often had to depend on their parents or guardians for a better future. The distribution of students based on stream have been graphically represented in the Figure 2.

Most of the students chose science as their field for their future career (19.3\%) followed by Eco / Admin (14.3\%) and Sharia \& Islam (11.6\%). Very less students opted for Medicine $(0.7 \%)$ and Dentistry (0.3 \%). 


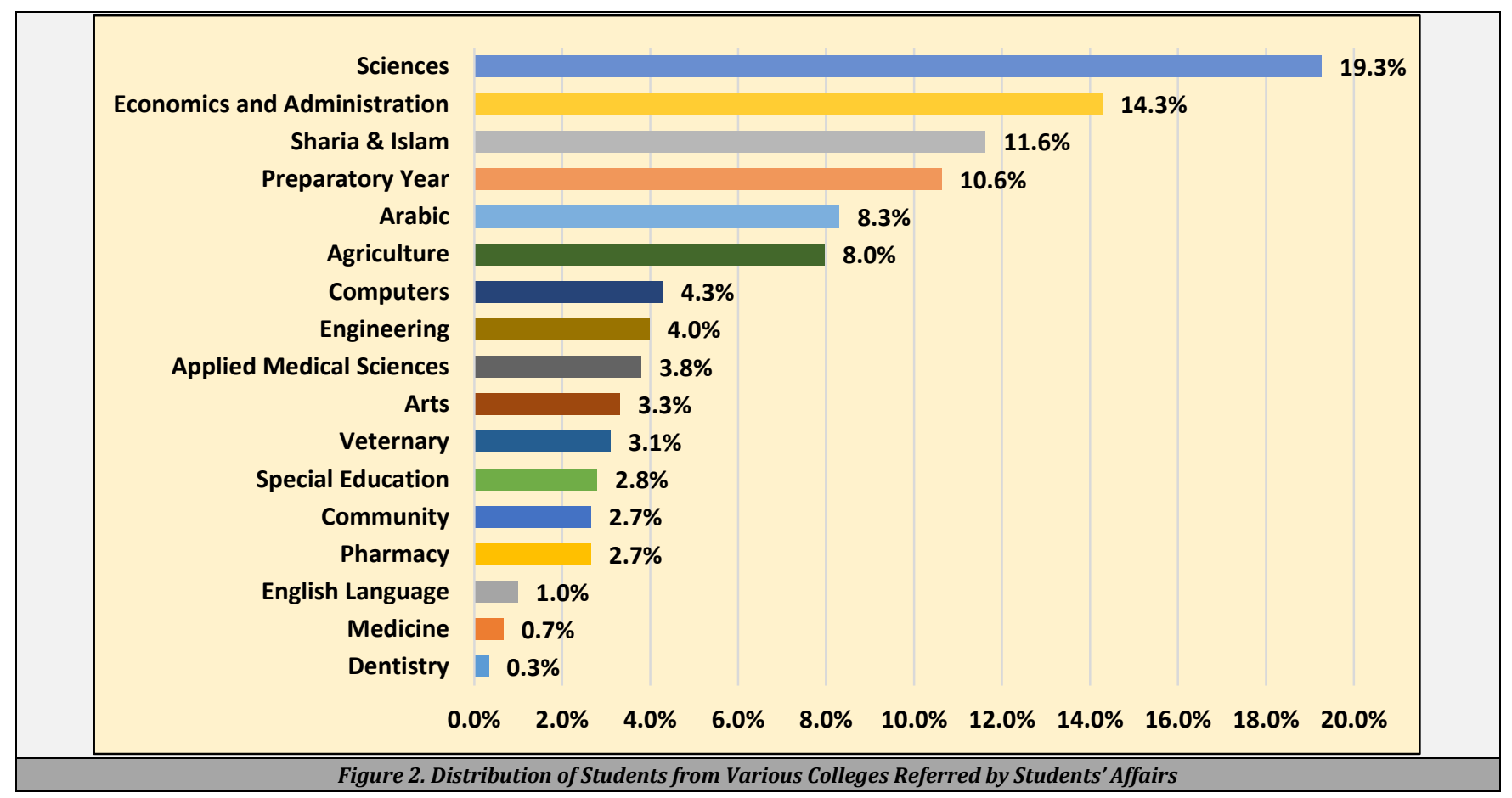

\section{DISCUSSION}

The educational landscape for university students with presence of disabilities is undergoing a vast change. Students who enrol with disabilities are the focus of attention, as it states the labour and efforts to improve their academic outcomes. Improvement of outcomes for students with disabilities and to what extent evidence-based practices are being used to make these policy decisions affects students with disabilities (such as visual acuity measurement depicts the role of one small central retinal area that has the maximum resolving power). There are a number of social rehabilitations, care and remedial services, designed to assist the physically disadvantaged, to protect vulnerable members of the society. One among this social services program is to rehabilitate the students with low vision or vision disability. The facilities and encouragement in education for university students with the prevalence of disabilities, has improved over the years. The enrolment of students with disabilities is the focus of attention, as efforts are made to improve their academic outcomes. Evidence based studies are being considered to script policies for the improvement in the students with disabilities. ${ }^{8}$ There are different social rehabilitations and remedial services with the objective of rehabilitating the students with low vision or vision disability. ${ }^{9}$

Previous studies have indicated the high prevalence of low vision and visual disability among student populations in Saudi Arabia, and a need for proper rehabilitation and social assistance to them to make their future secure. Most of the universities in Saudi Arabia are from public sector. Qassim University is a public university established in 2004 in the central part of Saudi Arabia. The total population of students at present in the university is around 70,000.10-12 In our study, $642(1 \%)$ of the university students were referred by student's affair for screening. The prevalence of low vision and visual disability among student in the university is $0.8 \%$. Only $13(0.02 \%)$ of university students benefitted with disability compensation. Keeping on mind that a low vision / disability benefit as provided by the universities is $50 \%$ of the total cost of the spectacles up to SR 250 for the students with refractive error and SR 1500 per month for the students with severe visual impairment. This leads us to the fact that the compensation will not add much on the universities budget, while it is of paramount important to the disabled students and universities has to continue practicing that. In addition, not all visually poor and disabled students will ask for compensation.

The most common conditions, which resulted in low vision were bilateral sub capsular cataract, resulting into stimulus deprivation amblyopia, high pathological myopia and advanced keratoconus. These conditions accounted for more than half of the causes. Given the fact that, these conditions if detected and treated early, the progress could have been halted. This needs very early screening programs, before the age of 5 years. As these screening programs are not available in the Kingdome of Saudi Arabia they should be initiated on a national base. Some of these conditions could be identified in routine school eye check-ups upon entering the first primary grade. 9,13 This routine check-up in Saudi Arabia is now done in primary care centres by general physicians. Their sensitivity to pick up and treat or refer these conditions still needs to be assessed.

Majority of students in the developing countries with visual impairment were from middle socio-economic class. ${ }^{14}$ Hence, there is dependence on their family for financial assistance, unlike in developed countries where such conditions are hardly prevalent. In the developed countries, students with disabilities have to compete with ordinary students for financial assistance in the form of scholarships provided by government which were insufficient to cover their expenses. ${ }^{1}$

In the developing countries, financial sustainability is an issue for poor families, and it is even more for students with vision disability. ${ }^{15}$ Though finance is an issue for all students belonging to poor families but it is more so for disabled students. This is because these students require special 
devices but it is unaffordable for such students. ${ }^{16}$

United States, both federal and state, funded rehabilitation programs and assists the students with vision disabilities for personal use and study. Enrolment of students with vision disability, for their postsecondary education at the university, are provided with books and resources, either taped or in Braille version. In addition to, the permission to use tape recorders, computer note, taking equipment in the classroom, access to Optacons (electronic devices that convert printed text to a raised, tactile finger pad) and tactile and large-print maps orientation to classrooms, buildings, and the campus. Financial aid for postsecondary education from the U.S. Department of Education's Federal Student Aid program is the most widely available source of funding for postsecondary education. Aid in the form of grants and low-interest loans is awarded based on financial need as determined by a formula that considers a family's income, assets, and expenses. ${ }^{17}$ Based on published data it was felt that a prevalence study on students seeking compensation for visual disability in Qassim University should be conducted.

\section{CONCLUSIONS}

Results are encouraging with respect to promoting compensatory rehabilitation for students with low vision and visual disability that impact their ability to carry out efficient learning. The study highlights the need for screening the children before school and to evaluate the current school screening practice. Training of visually challenged individuals by other professionals like physiotherapist or occupational therapist will help in better rehabilitation for the students who have ocular disorders associated with systemic disorders.

\section{Limitations of the Study}

There were no records available from female student section of the University hence are not included in study. If such clinics were setup in the female college, it would give a complete picture of the population.

Data sharing statement provided by the authors is available with the full text of this article at jemds.com.

Financial or other competing interests: The authors would like to thank the Deanship of Scientific Research at Majmaah University, Saudi Arabia for funding this research under project number (No. R2021-36).

Disclosure forms provided by the authors are available with the full text of this article at jemds.com.

Authors acknowledge the Deanship of student affairs, Qassim University for given the permission to conduct this Research. We would also like to acknowledge Dr. Yousef H. Aldebasi the then Dean of College of Applied Medical Sciences for allowing us to collect the data from the Department of Optometry.

\section{REFERENCES}

[1] Ali R, Hameed H. Dealing with visual impairment: experiences of youth in tertiary education. Social Sciences Review 2015;3(1):1-24.

[2] World Health Organization. The work of WHO in the Eastern Mediterranean Region: annual report of the Regional Director 1, January-31, December 2004.

[3] Al-Shaaln FF, Bakrman MA, Ibrahim AM, et al. Prevalence and causes of visual impairment among Saudi adults attending primary health care centers in northern Saudi Arabia. Annals of Saudi Medicine 2011;31(5):473-80.

[4] WHO. WHO criteria of visual impairment.

[5] Varma R, Wang MY, Ying-Lai M, et al. The prevalence and risk indicators of uncorrected refractive error and unmet refractive need in Latinos: The Los Angeles Latino Eye Study. Invest Ophthalmol Vis Sci 2008;49(12):5264-73.

[6] He M, Xu J, Yin $Q$, et al. Need and challenges of refractivecorrection in urban Chinese school children. Optom Vis Sci 2005;82(4):229-34.

[7] Pi LH, Chen L, Liu Q, et al. Refractive status and prevalence of refractive errors in suburban school-age children. Int J Med Sci 2010;7(6):342-53.

[8] Benz MR, Lindstrom L, Yovanoff P. Improving graduation and employment outcomes of students with disabilities: Predictive factors and student perspectives. Exceptional Children 2000;66(4):509-29.

[9] World Health Organization. Preventing blindness in children: report of WHO/IAPB 20 scientific meeting. Geneva: WHO, 2000. WHO/PBL/00.77.

[10] Al-Wadani F, Khandekar R, Al-Hussain MA, et al. Magnitude and causes of low vision disability (moderate and severe visual impairment) among students of Al-Noor institute for the blind in Al-Hassa, Saudi Arabia: a case series. Sultan Qaboos University Medical Journal 2012;12(1):62-8.

[11] Tabbara KF, El-Sheikh HF, Shawaf SS. Pattern of childhood blindness at a referral center in Saudi Arabia. Annals of Saudi Medicine 2005;25(1):18-21.

[12] Vora U, Khandekar R, Natrajan S, et al. Refractive error and visual functions in children with special needs compared with the first grade school students in Oman. Middle East African Journal of Ophthalmology 2010;17(4):297-302.

[13] Jose R, Sachdeva S. School eye screening and the National Program for Control of Blindness. Indian Pediatrics 2009;46(3):205-8.

[14] Ganesh S, Sethi S, Srivastav S, et al. Impact of low vision rehabilitation on functional vision performance of children with visual impairment. Oman Journal of Ophthalmology 2013;6(3):170-4.

[15] Fuller M, Bradley A, Healey M. Incorporating disabled students within an inclusive higher education environment. Disability \& Society 2004;19(5):455-68.

[16] Shamanna BR, Dandona L, Rao GN. Economic burden of blindness in India. Indian Journal of Ophthalmology 1998;46(3):169-72.

[17] Schneider K. Students who are blind or visually impaired in postsecondary education. The George Washington University HEATH Resource Center, 2001. 